\title{
Em 2021 a Labor \& Engenho é objeto de Estudo e publica 25 artig̉os, sendo que 10 deles compõem o Dossiê Documentação do Patrimônio Cultural orgaanizado pelo Comitê Nacional científico de Documentação do Icomos Brasil
}

\author{
André Munhoz de Argollo Ferrão \\ https://orcid.org/0000-0003-0687-3622 \\ Editor-chefe da Labor \& Engenho [ISSN 2176-8846] \\ Universidade Estadual de Campinas / Campinas [SP] Brasil \\ Alcilia Afonso de Albuquerque e Melo \\ https://orcid.org/0000-0002-6344-9329 \\ Universidade Federal de Campina Grande / Campina Grande [PB] Brasil \\ Coordenadora do Comitê Científico Nacional de Documentação do Icomos Brasil
}

\section{Editorial V.15 (2021)}

A revista Labor \& Engenho tem a satisfação de apresentar o seu volume 15, com 25 artigos de excelente qualidade, sendo que 10 deles compõem o "Dossiê Documentação do Patrimônio Cultural" organizado pelo Comitê Científico Nacional de Documentação do Icomos Brasil. Sabe-se que o Icomos - International Council on Monuments and Sites - é uma organização não governamental global, fundada em Veneza [Itália] no ano de 1964, para promover a conservação, proteção, uso e valorização de monumentos, sítios urbanos, naturais e rurais, paisagens e o patrimônio imaterial. O Comitê Brasileiro do Icomos foi fundado em 1978 no Rio de Janeiro. Desde 2016, o Icomos Brasil - Comitê Brasileiro do Conselho Internacional de Monumentos e Sítios - vem se reorganizando e criando representações regionais e estaduais, assim como os comitês científicos nacionais, dentre os quais o de "documentação", coordenado pela professora doutora Alcilia Afonso de Albuquerque e Melo [Alcilia Afonso], membro efetivo do Conselho Editorial da Labor \& Engenho, quem, nesta edição, apresenta o "Dossiê Documentação do Patrimônio Cultural", e assina o Editorial em coautoria com André Munhoz de Argollo Ferrão [André Argollo], o Editor-chefe da Labor \& Engenho.

No ano de 2021, o Conselho Editorial e a Equipe Editorial da Labor \& Engenho trabalharam de maneira muito integrada, graças às atuações de alguns de seus membros, a começar por André Argollo e Kaki Afonso que assinam este Editorial, mas também com especial destaque para as doutoras Danielle Ferreira e Priscila Coltri, membros do Conselho Editorial, muito participativas - tanto nos trabalhos de concepção e decisões editoriais, como nos trabalhos de supervisão e execução técnica de editoração.

Há de se reconhecer e valorizar os importantes trabalhos de Beatriz Lazaro (BAS/SAE-Unicamp) e de Luíza Melo da Silva (IEL-Unicamp e PAPI/SAE-Unicamp). A Beatriz atuando no apoio à editoração, inclusive nos trâmites de verificação dos Metadados no sistema SEER/OJS, sempre sob orientação do Conselho Editorial da revista. A Luíza, por sua vez, realizou um prestimoso trabalho de apoio à gestão, incluindo análise dos índices e do posicionamento gerencial da revista, gerando informações preciosas (Figura 1) para o Conselho Editorial. Trata-se do "Estudo Labor \& Engenho", apresentado em Congresso realizado na Unicamp, em Campinas [SP] no segundo semestre de 2021.
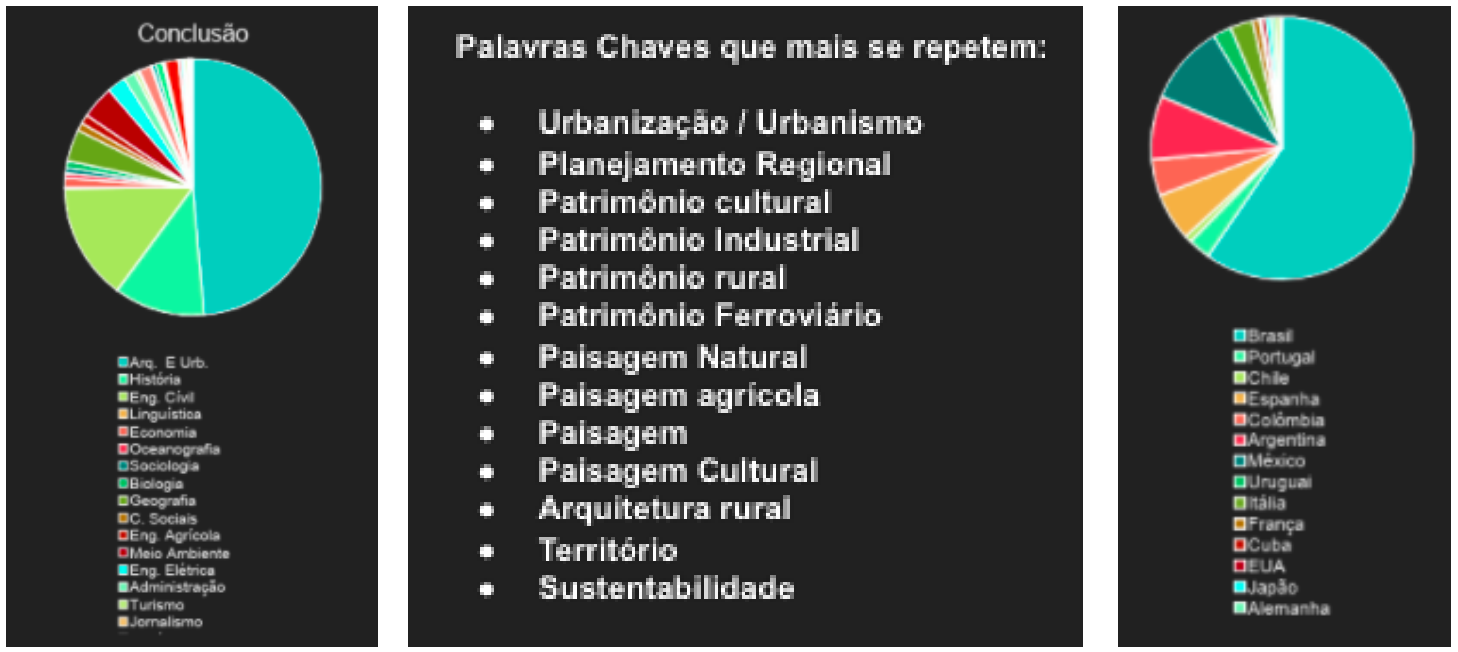

Figura 1. Alguns dos resultados apresentados no "Estudo Labor \& Engenho" [por] Luíza Melo da Silva, 2021. 
O "Estudo Labor \& Engenho" realizado por Luíza Melo da Silva apresentou resultados interessantes abstraídos da revista ao longo dos seus 15 anos de existência, como, por exemplo, a constatação das áreas de conhecimento mais presentes: Arquitetura e Urbanismo, História e Engenharia Civil, além de outras 12; alavancando, consequentemente, as palavras-chave mais utilizadas nos artigos publicados pela revista: Urbanização / urbanismo. Planejamento regional. Patrimônio cultural, industrial, rural, dentre as principais. $\mathrm{Ou}$, os países de origem dos autores que mais publicaram na revista, tendo o Brasil, obviamente, como destaque em primeiro lugar, seguido por México, Argentina, Espanha, Colômbia e mais 10 países, demonstrando a consolidação da Labor \& Engenho como opção de publicação em outros países, especialmente nos de língua espanhola, embora tenham sido publicados artigos também nos idiomas inglês, francês e italiano. Em 2022, a Labor \& Engenho entra no seu Ano 16.

\section{O INíCIO DE UM PASSEIO POR Belos TerRitórios E PAISAgENS}

O volume 15 (2021) da Labor \& Engenho se inicia com o artigo intitulado Espacos livres e águas residuais: contribuições do Lima Ecological Infrastructure Strategy (e021001), de autoria de Nayara Cristina Rosa Amorim (Universidade Federal da Bahia). O artigo visa analisar como o manual LEIS - Lima Ecological Infrastructure Strategy propõe a articulação do tratamento de águas residuais com o projeto dos espaços livres públicos em Lima [Peru]. O manual apresenta possibilidades de projetos sensíveis a água através do conceito de Infraestrutura Ecológica. A autora adota uma metodologia de análise qualitativa, concentrando-se na revisão bibliográfica e na consulta à legislação pertinente. Busca relacionar propostas e diretrizes presentes no manual com a gestão das águas urbanas em Salvador [BA].

O artigo Dinâmica do uso e ocupação da terra na bacia bidrográfica do Rio Fruteiras, Estado do Espirito Santo, Brasil (e021002), de Caio Henrique Ungarato Fiorese (Universidade Federal do Espírito Santo), reconhece a importância dos estudos de uso e ocupação de terras para a mitigação e atenuação dos impactos ambientais negativos à superfície do solo. Com foco na bacia hidrográfica do Rio Fruteiras, mesorregião Sul do Estado do Espírito Santo, o artigo procura avaliar o planejamento territorial e ambiental aliado ao crescimento econômico. A bacia estudada possui problemas quanto ao planejamento de suas terras e o aumento das áreas plantadas de eucalipto requer atenção por provocar impactos positivos e negativos. É relevante a atuação dos comitês de bacias hidrográficas, gestores públicos e produtores rurais, para o planejamento ambiental adequado associado à execução correta das atividades humanas.

A seguir, o artigo intitulado Entorno residencial y habitabilidad urbana en tiempos de pandemia: el caso de Xalapa [México] (e021003), dos autores mexicanos Mauricio Hernández-Bonilla e Karla Lorena Lozano-Merino (Universidad Veracruzana - ambos). Neste artigo, os autores expõem os resultados de uma pesquisa de opinião realizada entre os habitantes da cidade de Xalapa [estado de Veracruz] México. Resultados reveladores com relação à valorização do entorno das casas, e estas no contexto da emergência sanitária - por parte de seus usuários, posto que ficou claro a existência de deficiências relevantes quanto à habitabilidade nas casas e seu entorno imediato e em matéria de espaço público, segurança, coesão social - inclusive na própria convivência social dentro e fora das habitações.

Ainda no México, o artigo de Enrique Esteban Gómez Cavazos (Universidad Autonoma de Nuevo León), intitulado Lower California Development Company: historia de los restos urbanos y agroindustriales de la capital frustrada de las compañias norteamericana e inglesa en el porfiriato, San Quintín [Baja California] México (e021004), dá conta de que concessão territorial no fim do século XIX à Mexican Land and Colonization Company de capital britânico, que anos antes havia sido comprada à International Company of México de capital norte-americano, desenvolve um projeto inicial - econômico e urbanístico - tratando de construir uma colônia de irrigação para o vale de San Quintín e um centro agrícola potente como capital da companhia. O artigo tem como objetivo a busca na história industrial por peças nesse território que narrem a sua origem e descrevam a sua identidade.

Depois deste passeio pelo México (pelos estados de Veracruz e Baja California), já tendo passado pela Bahia (com um estudo sobre Lima, no Peru), e pelo estado do Espírito Santo, o leitor é convidado a visitar Minas Gerais. O artigo de Inácio Manuel Neves Frade da Cruz (Universidade do Estado de Minas Gerais), Luisa Souza Neves Frade da Cruz, Helena Souza Neves Frade da Cruz e Lucas Soares (Universidade Federal de Juiz de Fora - os três) intitulado Um olhar sobre passagens: proposições de uso do bambu nas pontes entre os distritos de Cataguases [MG] (e021005), convida à reflexão sobre algumas pontes e pontilhões de madeira, em estado de precariedade, nas estradas vicinais dos distritos de Cataguases [MG]. Nesta pesquisa, percorreu-se as vias de acesso às comunidades de Sereno, Glória de Cataguases e Cataguarino. Ao longo do trajeto, observou-se uma abundante presença do bambu na paisagem rural, inclusive, nas proximidades das pontes e pontilhões. 
DOSSIÊ DOCUMENTAÇÃO DO PATRIMÔNIO CULTURAL

Como coordenadora do Comitê Científico Nacional de Documentação do Icomos Brasil - o IcomosDoc Alcilia Afonso vem procurando promover e realizar publicações em formato de dossiês, compostos de artigos resultantes de pesquisas acadêmicas e atuações profissionais na área do patrimônio cultural brasileiro, produzidos pelos membros que compõem o mencionado comitê.

A proposta é divulgar ações que são de fundamental importância nas mais distintas atividades que compõem o trabalho de ativismo patrimonial no país... - "sempre tenho dito" (diz Alcilia Afonso) que "documentar é o primeiro passo prático da ação preservacionista, pois coleta e cria subsídios para intervenções para a conservação dos acervos culturais, sejam estes, materiais ou imateriais". Resgatar imagens, falas, documentos em fontes primárias ou secundárias, tratar o bem material como documento, seja ele um edifício, um conjunto arquitetônico, paisagístico ou mesmo urbanístico, faz parte deste trabalho. Utilizar-se de ferramentas analógicas ou digitais, antigas ou novas, mas sempre procurando trazer à tona informações necessárias e imprescindíveis para tentar realizar algo concreto em prol da preservação patrimonial.

Como membro do Conselho Editorial da Labor \& Engenho, Alcilia Afonso propôs-se a organizar o Dossiê Documentação do Patrimônio Cultural, vinculado ao Comitê Científico Nacional do Icomos Brasil, com 10 artigos selecionados para compor esta edição - volume 15 da revista Labor \& Engenho.

Os artigos do dossiê apresentam resultados de estudos realizados em todas as regiões brasileiras e nos trazem uma amostragem de casos de norte a sul do Brasil, escritos por membros do IcomosDoc, individualmente ou em coautoria com pesquisadores atuantes em seus respectivos grupos de pesquisa, de modo a nos oferecerem reflexões pertinentes às suas realidades locais, que estão direta ou indiretamente vinculadas à política cultural brasileira.

Da região Norte do Brasil, o artigo Historiografia digital da Arquitetura Moderna em Belém [PA]: o website 'Morar Moderno' como experiência de documentação e divulgação (e021022), de autoria de Celma Chaves, Bernadeth Beltrão, e Rebeca Dias, nos apresenta informações sobre o projeto "Morar Moderno", desenvolvido por meio da Lei Federal no 14.017/20, do Edital Patrimônio Cultural Material - Lei Aldir Blanc Pará 2020, e realizado pelo Coletivo Cultura Arquitetônica, Amazônia e Modernidade (CAAM). Neste artigo, foi explorada uma estratégia de educação patrimonial que visa a divulgação e reconhecimento da arquitetura moderna residencial produzida em Belém [PA] e a criação de um website como resposta a essa necessidade, evidenciando suas etapas de desenvolvimento. $\mathrm{O}$ artigo atesta que a formalização de um projeto nesta temática visa criar condições para que a população conheça e reconheça o Patrimônio Moderno edificado em Belém e possa contribuir com práticas para preservá-lo.

Pela região Centro-Oeste do Brasil foram produzidos três artigos para o dossiê: dois sobre bens culturais da cidade de Goiânia [GO], e um artigo sobre o Catetinho, em Brasília [DF].

O primeiro artigo enfoca o Coreto Art Déco em Goiânia: vicissitudes de um patrimônio reconhecido (e021008) das autoras Eline Maria Mora Pereira Caixeta e Marília Mota Rezende (Universidade Federal de Goiás - ambas), e trata sobre este bem tombado pelo Iphan, que sofreu diversas alterações físicas ao longo de sua história, tendo sido inclusive descaracterizado, e posteriormente, reconstruído, fato muitas vezes ocultado dos registros oficiais. O artigo objetiva a construção de uma historiografia das intervenções arquitetônicas sofridas, destacando as dinâmicas que trouxeram o Coreto à sua configuração atual e as relações entre identidade e memória nesse processo. O segundo artigo, de autoria de Eliel Américo Santana da Silva (Universidade de Brasília), Juan Carlos Guillen-Salas (Universidade de Brasilia) e Luana Miranda Esper Kallas (Universidade Federal de Goiás), possui como título: Representação e história da antiga estação ferroviária de Goiânia e da antiga rodoferroviária de Brasilia documentadas por sketches (e021016). O objetivo do artigo foi apresentar a história e uma representação da antiga Estação Ferroviária de Goiânia e da antiga Rodoferroviária de Brasília documentada por sketches.

O terceiro artigo da região Centro-Oeste a compor o dossiê é representado no Sumário da revista pela bandeira de Portugal, uma vez que um dos autores encontra-se vinculado a uma universidade portuguesa. O artigo se intitula Catetinho: patrimonialização e arquitetura efêmera (e021017), de autoria de Marina Martins Mennucci (Universidade de Aveiro) e Pedro Paulo Palazzo (Universidade de Brasilia). Enfoca o edifício construído em 1956, próximo ao canteiro de obras de Brasília, e é a única obra existente de Oscar Niemeyer em madeira, que foi destinada a servir de gabinete provisório ao Presidente da República durante a construção da nova capital. O texto discute o estado atual de conservação do Catetinho, como suas técnicas de projeto e construção 
impactam a sabedoria convencional na preservação de edifícios modernistas e de madeira, e estratégias recomendadas para proteger a integridade do material e a inteligibilidade de seu projeto original.

Da região Nordeste foram produzidos dois artigos: um sobre a cidade histórica de Parnaíba, no litoral piauiense; e outro sobre a cidade turística de Campina Grande, na Paraíba.

O artigo Narrativas da paisagem como documentação patrimonial urbana e arquitetônica: o caso de Parnaíba [PI] (e021006) de autoria de Isis Meireles Rodrigues (Centro Universitário Uninovafapi) e Celina Borges Lemos (Universidade Federal de Minas Gerais) trata das dimensões material e imaterial da paisagem urbana e ambiental de Parnaíba [PI], fruto da polaridade entre o centro antigo e a crescente expansão urbana que ocorre no cotidiano das cidades contemporâneas. O objetivo geral é compreender quais narrativas da paisagem emergem do patrimônio arquitetônico e urbano local, e de que forma as mesmas interferem na salvaguarda do patrimônio no conjunto analisado. As autoras esperam, a partir dos resultados encontrados, refletir sobre os caminhos possíveis para uma gestão e salvaguarda mais eficaz do patrimônio no século XXI.

Por sua vez, Documentando o bairro de Bodocongó em Campina Grande [PB]: diálogo entre arquitetura, paisagem e patrimônio industrial (e021011), de autoria Alcilia Afonso com os pesquisadores Ivanilson Santos e Lucas de Souza Jales (Universidade Federal de Campina Grande - os três autores), é o segundo artigo do dossiê voltado para a problemática nordestina. O texto possui como objeto de estudo a análise da paisagem natural e construída do bairro de Bodocongó em Campina Grande [PB] - agreste paraibano do nordeste brasileiro - que teve sua origem e consolidação vinculadas ao processo de modernização e industrialização regional, ocorridos nas décadas de 50 a 70 do século XX. O objetivo é observar o diálogo entre arquitetura, paisagem e patrimônio industrial, refletindo sobre as mudanças sofridas nas paisagens naturais e construídas deste bairro ao longo de sete décadas, baseadas em documentos originais e gerados pela pesquisa, analisando-se o que foi mantido de sua paisagem natural, e de sua história arquitetônica vinculada ao segmento industrial.

Abrangendo a região Sudeste do Brasil foram produzidos no âmbito do dossiê mais três artigos: um para documentar e analisar redes ferroviárias, tomando como exemplo o caso de Ribeirão Preto [SP]. No artigo Patrimônio ferroviário e SIG histórico: para além das estaçôes (e021012), os autores Gustavo Nogueira Zeoti (Prefeitura Municipal de Ribeirão Preto), Ana Teresa Cirigliano Villela (Universidade de São Paulo e Centro Universitário Barão de Mauá), e Adriana Capretz Borges da Silva Manhas (Universidade Federal de Alagoas) utilizaram dados sistematizados em SIG, que serviram como suporte para reconstituir a rede ferroviária do município ao longo dos anos, a partir de documentação cartográfica, bibliográfica, iconográfica e de vestígios materiais. Como contribuição, o artigo evidencia a importância histórica de outros elementos do patrimônio ferroviário, para além das estações, trazendo reflexões acerca dos critérios empregados nas políticas de preservação dos bens culturais do município. A mesma sistemática pode ser empregada em outras localidades e conformar um SIG histórico-ferroviário em escala regional.

Outro artigo do dossiê que aborda a região Sudeste tem como foco a cidade do Rio de Janeiro [RJ], e possui como título: Os Jardins da 'Belle Époque Carioca': documentação paisagística do período Pereira Passos (e021009), de autoria de Alda Azevedo Ferreira (Universidade Federal do Rio de Janeiro). O artigo reflete sobre as reformas paisagísticas ocorridas na cidade do Rio de Janeiro no início do século XX, com ênfase para a prática projetual de Paul Villon e sua equipe. Baseado em fontes primárias e no conceito de habitus, de Pierre Bourdieu, observou-se que, nesse momento, ocorreu a primeira nomeação para a função de arquiteto paisagista, concedida a Paul Villon, que juntamente com sua equipe, ficou encarregado pela concepção dos jardins no Período Pereira Passos.

O terceiro trabalho representando a região Sudeste do Brasil no dossiê trata do Programa ICMS Patrimônio Cultural: 25 anos de municipalização da gestão de bens protegidos em Minas Gerais (e021020), artigo de Clarice de Assis Libânio e Camila Silva Morais (Universidade Federal de Minas Gerais - ambas), abordando de forma sistemática e histórica a criação e consolidação da Lei Robin Hood em Minas Gerais e do Programa ICMS Patrimônio Cultural, instrumento de normatização para implementação do critério patrimônio cultural da referida Lei pelas municipalidades. Apresenta e explicita as diretrizes e normativas elaboradas pelo IEPHA/MG, responsável pela coordenação do Programa, voltadas para a gestão, proteção, salvaguarda e promoção do patrimônio cultural local, inclusive as alternativas buscadas para o período da pandemia.

Finalmente, representado o Sul brasileiro na seleção do dossiê, o artigo intitulado O Sítio da Faz̧enda do Arado, seus patrimônios e sua importância cultural para Porto Alegre [RS] e região, de autoria de Rosilene Martins Possamai 
(Prefeitura Municipal de Porto Alegre) e da arqueóloga Fernanda Bordin Tocchetto. O artigo trata da importância da antiga Fazenda do Arado localizada no Bairro Belém Novo, Zona Sul de Porto Alegre [RS], como patrimônio cultural para a cidade e a região, tendo por base os estudos interdisciplinares realizados pela Secretaria Municipal da Cultura (SMC) na área rural do município, entre os anos de 2010 e 2016. A área da antiga Fazenda se encontra ameaçada por projeto para implantação de empreendimento urbanístico de condomínio por unidades autônomas, de impacto considerável sobre as características da zona rural. Os estudos arqueológicos para licenciamento ambiental e as pesquisas dos técnicos da SMC evidenciaram os diversos patrimônios culturais do local, resultando na proteção da área em nível municipal e federal. Concomitantemente, movimentos comunitários e ambientais, bem como ações judiciais lutam pela sua preservação, enquanto se contrapõem tentativas de mudança na legislação para aprovação do projeto de condomínio.

Dessa maneira, com o "Dossiê Documentação do Patrimônio Cultural" organizado pelo Comitê Científico Nacional de Documentação do Icomos Brasil, realiza-se um "passeio" pela diversidade patrimonial cultural brasileira, com características tão distintas, mas ao mesmo tempo, com pontos convergentes relativos ao cenário das políticas públicas nacionais. Artigos que certamente se constituirão como referência para novas pesquisas, e embasamentos - para aprofundar outras. A missão do IcomosDoc é essa: provocar reflexões, produzir contribuições. Boa leitura a todos!

\section{CONTINUANDO O PASSEIO POR BELOS TERRITÓRIOS E PAISAgENS}

Dando continuidade ao "passeio" por belos territórios e paisagens oferecido pela revista Labor \& Engenho em seu volume 15 (2021), o leitor é convidado conhecer O projeto do calçadão de Santa Maria [RS] (e021007), lendo o artigo de Felipe Bassan Marinho Maciel (Universidade Federal do Rio Grande do Sul), que realiza uma entrevista com o arquiteto Luiz Gonzaga Binato de Almeida (autor do projeto), quem - ao responder as questões que se interpõem - acaba falando sobre a concepção do projeto original do calçadão de Santa Maria [RS] de 1979, e reflete a respeito dos seus mais de 40 anos de ocupação.

O "Estudo Labor \& Engenho" (Melo da Silva, 2021) mostra que a publicação de artigos no idioma inglês não é uma novidade para a revista Labor \& Engenho. No entanto, em 2021, o único artigo publicado em inglês tratou sobre as mudanças ocorridas no estado do Paraná com respeito à cobertura do solo pelas áreas ocupadas pela cafeicultura. O artigo Change analyses of coffee soil cover in the state of Parana [Brazil]: a case study (e021010), de José Gabriel Vaz de Lima (Centro Universitário Adventista de São Paulo) e Priscila Pereira Coltri (Universidade Estadual de Campinas), constata que entre 1998 e 2018 houve uma redução de 92,29\% da área plantada de café no Paraná contra um aumento de $289,87 \%$ da área plantada de cana-de-açúcar, sugerindo que o café foi substituído pela cana em muitas áreas paranaenses, cujas plantações remanescentes se concentraram na região Norte do Paraná, onde há um café de excelente qualidade, reconhecido por sua indicação de origem.

Do Paraná voltamos a Goiás, desta vez para desfrutarmos das Crônicas de Rachel de Queiroz e a cidade de Goiás: um familiar olhar estrangeiro (e021013), artigo de Irina Alencar de Oliveira (Universidade de Brasília), que investiga o imaginário urbano criado pela escritora Rachel de Queiroz sobre a cidade de Goiás, observado através de algumas de suas crônicas jornalísticas que contemplam essa temática, publicadas entre 1948 e 1988. Utiliza-se a História Cultural como suporte teórico-metodológico, sendo exploradas as complexas relações entre história e ficção e abordando o conceito de imaginário urbano, a partir dos discursos e imagens vinculados a Goiás refletidos pela autora.

Da cidade de Goiás [GO] pelas crônicas de Rachel de Queiroz vamos para Jundiaí [SP], observar Pelas lentes dos Janczur: a fotografia como representação da vida urbana no início do século XX em Jundiaí [SP] (e021015) o que o artigo de Jean Marcel Caum Camoleze e Bruno Henrique Machado (Universidade Estadual Paulista ambos) tem a nos ensinar sobre esta importante cidade do interior de São Paulo. Utilizando o acervo fotográfico de Alexandre Janczur e João José Janczur, o estudo pretende expor um recorte da cidade de Jundiaí [SP] no início do século XX, suas vicissitudes e a importância da imagem fotográfica na sociedade. Desta forma, analisa-se a fotografia não apenas como um registro do presente, mas também como ato fundamental na compreensão do passado e na formação da memória coletiva.

Seguiremos no interior de São Paulo para conhecer a Construção do espaço saudável reverberações micro e macro: experiência do Viveiro Municipal de Hortas Medicinais e Alimentícias em Santa Bárbara d'Oeste [SP] (e021019), artigo de 
Ana Maria Girotti Sperandio e Tailana Fraga Lima (Universidade Estadual de Campinas - ambas), que oferece uma descrição sistematizada das ações desenvolvidas por um grupo de mulheres para a construção de um espaço coletivo e plural a partir do cultivo de Plantas Alimentícias e Medicinais, materializando-se na experiência do Viveiro Municipal de Santa Bárbara d'Oeste [SP], que ocupou um espaço urbano.

\section{FinALIZANDO O PASSEIO PELO VOLUME 15 (2021) COM PRINCÍPIOS E CONCEITOS}

Um relato histórico de estudos e o estado da arte no que se refere ao conceito de "Telhados Verdes" nas políticas públicas ambientais e nas pesquisas relacionadas à mitigação das inundações urbanas é apresentado no trabalho de Bárbara Roberta de Morais, Juan David Méndez-Quintero, Diego Rodrigues Macedo, e Marcelo Antônio Nero (todos da Universidade Federal de Minas Gerais). Para tanto, realizou-se no artigo Os telhados verdes nas políticas ambientais e como medida mitigadora das inundacooes urbanas: uma revisão sistemática (e021018) uma revisão bibliográfica histórica das técnicas e estudos utilizados nos últimos 15 anos em processos de gestão e planejamento para a implantação de telhados verdes como medida mitigadora das inundações urbanas. Foram utilizados os repositórios de busca Scopus, Periódicos da Capes e Scielo.

A ideia de "Ordenamento Territorial" como instrumento de planejamento e gestão do território é um processo ainda em desenvolvimento no Brasil. A proteção e a gestão do ambiente em consonância com a organização física do território constituem domínios distintos em estreita inter-relação, essenciais para um desenvolvimento equilibrado e sustentável, de acordo com o artigo Ordenamento do Território e Avaliação de Impacto Ambiental: uma breve revisão para reflexões pertinentes (e021025), de André Argollo (Universidade Estadual de Campinas). O texto apresenta uma coletânea de leis que permitem concluir que a Avaliação de Impacto Ambiental e o processo de licenciamento ambiental podem ser considerados como uma prática de ordenamento territorial.

A Labor \& Engenho oferece em seu volume 15 mais dois trabalhos de autores mexicanos - totalizando 4 artigos produzidos em universidades mexicanas, em 2021 - abordando diferentes regiões daquele importante país da América Latina - que possui muitos aspectos semelhantes ao contexto brasileiro. No artigo Estudio de perspectiva sobre la implementación de arquitectura adaptable en el mercado habitacional: postura de diseñadores de vivenda (e021021), de Francisco Mercado Diaz de Leon, Fernando Padilla Lozano, e Alejandra Torres Landa López (todos da Universidad Autónoma de Aguascalientes), os autores observam que na região em que vivem, nos últimos anos houve um aumento do interesse pela redução do consumo de recursos a fim de se obter um maior nível de sustentabilidade, valorizando soluções arquitetônicas adaptadas às necessidades dos usuários, aumentando o ciclo de vida dos edifícios e reduzindo a pegada ecológica. Por outro lado, Jonathan Hammurabi González Lugo e Martha Yolanda Pérez Barragán (Universidad Autónoma de San Luis Potosí - ambos), no artigo Negociaciones en la producción social de un espacio público. Colonias populares de San Luis Potosí, México (e021023) observam que embora as cidades devessem oferecer espaços para o encontro e a convivência a todo habitante, em alguns assentamentos populares da região onde vivem há uma carência de áreas que respondam a esta necessidade, o que leva os moradores a buscarem por áreas em desuso e, mediante negociações, as habilitem e as utilizem para atividades sociais, criando seus próprios lugares de encontro.

Para finalizar o passeio pelo volume 15 (2021) da Labor \& Engenho, nada como uma boa leitura do já frequente colaborador da revista, Zanoni Neves (Museu Antropológico do Vale do São Francisco), que ressalta em seu artigo Afonso Arinos e o Setão (e021024) que as origens rurais deste importante personagem da cultura brasileira explicam a essência de sua obra literária. Afonso Arinos de Melo Franco nasceu em Paracatu [MG] no dia 1º de maio de 1868 - faleceu em Barcelona [Espanha] em 19 de fevereiro de 1916. Foi jornalista, escritor e jurista, ocupou a cadeira 40 da Academia Brasileira de Letras, para a qual foi eleito em 31 de dezembro de 1901, sendo recebido em 18 de setembro de 1903 pelas mãos do acadêmico Olavo Bilac. Em linhas gerais, Arinos inclui-se no movimento literário denominado regionalismo, que deita raízes no romantismo de Franklin Távora e de outros autores de mesma orientação. Em seu livro "Pelo Sertão", obra seminal da literatura brasileira, Arinos bebe na fonte das classes populares: a linguagem, os temas, a mitologia, os personagens (tipos regionais), são inspirados em suas vivências no município de Paracatu, onde nasceu e onde sempre viveram parentes próximos. Outro traço marcante de sua literatura é, sem dúvida, o cerrado com sua fauna e flora, bioma onde se localiza sua cidade natal.

Em 2022 a Labor \& Engenho continuará oferecendo, em seu volume 16 (publicação continuada), um maravilhoso passeio por paisagens e culturas espetaculares, revelando aspectos do ambiente e o valor do maior patrimônio que uma sociedade pode ter: o seu território. Sigamos em frente! 
Reierências

\section{SUMARIO LABOR \& ENGENHO V.15 (2021) EM ORDEM ALFABÉTICA}

Amorim, N. C. R. (2021). Espaços livres e águas residuais: contribuições do Lima Ecological Infrastructure Strategy. Labor \& Engenho, 15, e021001. https://doi.org/10.20396/labore.v15i00.8664428

Argollo Ferrão, A. M. de (2021). Ordenamento do Território e Avaliação de Impacto Ambiental: uma breve revisão para reflexões pertinentes. Labor \& Engenho, 15, e021025. https://doi.org/10.20396/labore.v15i00.8668036

Chaves, C., Beltrão, B., \& Dias, R. (2021). Historiografia digital da Arquitetura Moderna em Belém [PA]: o website Morar Moderno como experiência de documentação e divulgação. Labor \& Engenho, 15, e021022. https://doi.org/10.20396/labore.v15i00.8665945

Caixeta, E. M. M. P., \& Rezende, M. M. (2021). Coreto art Déco em Goiânia: vicissitudes de um patrimônio reconhecido. Labor \& Engenho, 15, e021008. https://doi.org/10.20396/labore.v15i00.8665729

Camoleze, J. M. C., \& Machado, B. H. (2021). Pelas lentes dos Janczur: a fotografia como representação da vida urbana no início do século XX em Jundiaí [SP]. Labor \& Engenho, 15, e021015.

https://doi.org/10.20396/labore.v15i00.8665043

Cruz, I. M. N. F. da, Cruz, L. S. N. F. da, Cruz, H. S. N. F. da, \& Soares, L. (2021). Um olhar sobre passagens: proposições de uso do bambu nas pontes entre os distritos de Cataguases [MG]. Labor \& Engenho, 15, e021005. https://doi.org/10.20396/labore.v15i00.8664155

Diaz de Leon, F. M., Padilla Lozano, F., \& López, A. T. L. (2021). Estudio de perspectiva sobre la implementación de arquitectura adaptable en el mercado habitacional: postura de diseñadores de vivienda. Labor \& Engenho, 15, e021021. https://doi.org/10.20396/labore.v15i00.8665673

Ferreira, A. A. (2021). Os Jardins da 'Belle Époque Carioca': documentação paisagística do período Pereira Passos. Labor \& Engenho, 15, e021009. https://doi.org/10.20396/labore.v15i00.8665715

Fiorese, C. H. U. (2021). Dinâmica do uso e ocupação da terra na bacia hidrográfica do Rio Fruteiras, Estado do Espírito Santo, Brasil. Labor \& Engenho, 15, e021002. https://doi.org/10.20396/labore.v15i00.8659875

Gómez Cavazos, E. E. (2021). Lower California Development Company: historia de los restos urbanos y agroindustriales de la capital frustrada de las compañías norteamericana e inglesa en el porfiriato, San Quintín [Baja California] México. Labor \& Engenho, 15, e021004. https://doi.org/10.20396/labore.v15i00.8663983

González Lugo, J. H., \& Pérez Barragán, M. Y. (2021). Negociaciones en la producción social de un espacio público: Colonias populares de San Luis Potosí, México. Labor \& Engenho, 15, e021023. https://doi.org/10.20396/labore.v15i00.8665392

Hernández-Bonilla, M., \& Lozano-Merino, K. L. (2021). Entorno residencial y habitabilidad urbana en tiempos de pandemia: el caso de Xalapa [México]. Labor \& Engenho, 15, e021003. https://doi.org/10.20396/labore.v15i00.8665852

Libânio, C. de A., \& Morais, C. S. (2021). Programa ICMS Patrimônio Cultural: 25 anos de municipalização da gestão de bens protegidos em Minas Gerais. Labor \& Engenho, 15, e021020.

https://doi.org/10.20396/labore.v15i00.8665938

Maciel, F. B. M. (2021). O projeto do calçadão de Santa Maria [RS]: entrevista com o arquiteto Luiz Gonzaga Binato de Almeida. Labor \& Engenho, 15, e021007. https://doi.org/10.20396/labore.v15i00.8664871

Melo, A. A. de A., Pereira, I. S., \& Jales, L. de S. (2021). Documentando o bairro de Bodocongó em Campina Grande [PB]: diálogo entre arquitetura, paisagem e patrimônio industrial. Labor \& Engenho, 15, e021011. https://doi.org/10.20396/labore.v15i00.8665816

Mennucci, M. M., \& Palazzo, P. P. (2021). Catetinho: patrimonialização e arquitetura efêmera. Labor \& Engenho, 15 , e021017. https://doi.org/10.20396/labore.v15i00.8665935

Morais, B. R., Méndez-Quintero, J. D., Macedo, D. R., \& Nero, M. A. (2021). Os telhados verdes nas políticas ambientais e como medida mitigadora das inundações urbanas: uma revisão sistemática. Labor \& Engenho, 15, e021018. https://doi.org/10.20396/labore.v15i00.8663910

Neves, Z. (2021). Afonso Arinos e o Sertão. Labor \& Engenho, 15, e021024.

https://doi.org/10.20396/labore.v15i00.8667307 
Oliveira, I. A. de (2021). Crônicas de Rachel de Queiroz e a cidade de Goiás: um familiar olhar estrangeiro. Labor \& Engenho, 15, e021013. https://doi.org/10.20396/labore.v15i00.8665805

Possamai, R. M., \& Tocchetto, F. B. (2021). O Sítio da Fazenda do Arado, seus patrimônios e sua importância cultural para Porto Alegre [RS] e região. Labor \& Engenho, 15, e021014.

https://doi.org/10.20396/labore.v15i00.8665926

Rodrigues, I. M., \& Lemos, C. B. (2021). Narrativas da paisagem como documentação patrimonial urbana e arquitetônica: o caso de Parnaíba [PI]. Labor \& Engenho, 15, e021006. https://doi.org/10.20396/labore.v15i00.8665551

Silva, E. A. S. da, Guillen-Salas, J. C., \& Kallas, L. M. E. (2021). Representação e história da antiga estação ferroviária de Goiânia e da antiga rodoferroviária de Brasília documentadas por sketches. Labor \& Engenho, 15, e021016. https://doi.org/10.20396/labore.v15i00.8666174

Sperandio, A. M. G., \& Lima, T. F. (2021). Construção do espaço saudável reverberações micro e macro: experiência do Viveiro Municipal de Hortas Medicinais e Alimentícias em Santa Bárbara d’Oeste [SP]. Labor \& Engenho, 15, e021019. https://doi.org/10.20396/labore.v15i00.8666672

Vaz de Lima, J. G., \& Coltri, P. P. (2021). Change analyses of coffee soil cover in the state of Parana [Brazil]: a case study. Labor \& Engenho, 15, e021010. https://doi.org/10.20396/labore.v15i00.8666058

Zeoti, G. N., Villela, A. T. C., \& Manhas, A. C. B. da S. (2021). Patrimônio ferroviário e SIG histórico: para além das estações. Labor \& Engenho, 15, e021012. https://doi.org/10.20396/labore.v15i00.8665804 